\title{
BIBECHANA
}

\section{Complex formation in liquid potassium-lead alloy}

\author{
B.P. Singh ${ }^{a *}$, D. Adhikaria , I. S. Jha ${ }^{b}$, B.K. Singh ${ }^{a}$ \\ ${ }^{a}$ Univ. Dept. of Physics, T. M. Bhag. University, Bhagalpur, Bihar, India \\ ${ }^{\mathrm{b}}$ Dept. of Physics, M.M.A.M. Campus (Tribhuvan University), Biratnagar, Nepal \\ Article history: Received 24 September 2010; Accepted 25 October 2010
}

Abstract

Regular associated solution model has been used to study the mixing properties of $\mathrm{KPb}$ liquid alloy at $848 \mathrm{~K}$. The values of different thermodynamic parameters obtained from this model are compared with corresponding experimental values. Most of the computed values are in good agreement with the observed values.

\section{Keywords: Compound forming alloy; Pairwise interaction energy; Equilibrium constant}

\section{Introduction}

Liquid alloys, which are disordered systems in the sense of having no long-range atomic or magnetic order, display a remarkable variety of local chemical order. The free energy of mixing, heat of mixing and entropy of mixing of several liquid alloys are asymmetric with respect to concentration. The knowledge of thermodynamic and microscopic properties of binary liquid alloys is necessary for the design and development of reliable materials for high temperature application. The purpose of present investigation is to study energetic and structural properties of potassium lead alloy in molten state.

Potassium lead alloy in molten state is strongly compound forming alloy [1]. The phase diagram of $\mathrm{KPb}$ [2] lists $\mathrm{KPb}$ and $\mathrm{KPb}_{2}$ intermediate compounds in solid state. The formation of compound in solid state led many theoreticians to believe the existence of strong associations present in the alloy in molten state near melting temperature [4-13].

In this paper, we have calculated the equilibrium concentration of complex assuming $\mathrm{KPb}_{2}$ complex present in liquid state of $\mathrm{KPb}$ alloy at $848 \mathrm{~K}$ on the basis of regular associated solution model. We have then used these concentrations to calculate free energy of mixing $(\Delta \mathrm{G})$, heat of mixing $(\Delta \mathrm{H})$, entropy of mixing $(\Delta \mathrm{S})$ and activities of pure species in liquid $\mathrm{KPb}$ alloy.

\section{Model Basis}

Suppose type $\mathrm{A}(=\mathrm{Pb})$ and type $\mathrm{B}(=\mathrm{K})$ metals are mixed in the melt to form alloy $\mathrm{AB}$ $(=\mathrm{PbK})$. According to regular associated solution model, the melt consists of three species namely unassociated A-atoms, unassociated B-atoms and complex AB. Considering a solution of $n_{1}$

\footnotetext{
* Corresponding author: Dr. B.P. Singh, Univ. Department of Physics, T. M. Bhagalpur University, Bhag. India, Email: bhrigunandan@gmail.com
} 
atoms of $A$ and $n_{2}$ atoms of $B$, the formation of $n_{A p B}$ complex requires $n_{1}=n_{A}+p n_{A p B}$ and $\mathrm{n}_{2}=\mathrm{n}_{\mathrm{B}}+\mathrm{n}_{\mathrm{ApB}}$ for conservation of mass in the partially associated solution, where $\mathrm{n}_{\mathrm{A}}, \mathrm{n}_{\mathrm{B}}$, and $\mathrm{n}_{\mathrm{ApB}}$ are concentration of unassociated A-atoms, B- atoms and complex respectively where $\mathrm{p}$ is small integer. When there is association, the thermodynamic behaviour of complexes $\mathrm{A}$ and $\mathrm{B}$ components is governed by their true mole fractions $\mathrm{x}_{\mathrm{A}}, \mathrm{x}_{\mathrm{B}}$ and $\mathrm{x}_{\mathrm{ApB}}$ rather than their gross mole fraction $x_{1}$ and $x_{2}$, where $\quad \mathrm{x}_{1}=\frac{\mathrm{n}_{1}}{\mathrm{n}_{1}+\mathrm{n}_{2}}, \quad \mathrm{x}_{2}=\frac{\mathrm{n}_{2}}{\mathrm{n}_{1}+\mathrm{n}_{2}} \quad \mathrm{x}_{\mathrm{A}}=\frac{\mathrm{n}_{\mathrm{A}}}{\mathrm{n}_{\mathrm{A}}+\mathrm{n}_{\mathrm{B}}+\mathrm{n}_{\mathrm{ApB}}}$, $\mathrm{x}_{\mathrm{B}}=\frac{\mathrm{n}_{\mathrm{B}}}{\mathrm{n}_{\mathrm{A}}+\mathrm{n}_{\mathrm{B}}+\mathrm{n}_{\mathrm{ApB}}}$ and $\mathrm{x}_{\mathrm{ApB}}=\frac{\mathrm{n}_{\mathrm{ApB}}}{\mathrm{n}_{\mathrm{A}}+\mathrm{n}_{\mathrm{B}}+\mathrm{n}_{\mathrm{ApB}}}$

The free energy of mixing in regular associated solution model of given by [14]

$$
\begin{aligned}
& \Delta \mathrm{G}=\frac{1}{\left(1+2 \mathrm{x}_{\mathrm{A}_{2} \mathrm{~B}}\right)}\left[\left(\mathrm{x}_{\mathrm{A}} \mathrm{x}_{\mathrm{B}} \omega_{12}+\mathrm{x}_{\mathrm{A}} \mathrm{x}_{\mathrm{A}_{2} \mathrm{~B}} \omega_{13}+\mathrm{x}_{\mathrm{B}} \mathrm{x}_{\mathrm{A}_{2} \mathrm{~B}} \omega_{23}\right)+\mathrm{RT}\left(\mathrm{x}_{\mathrm{A}} \ln \mathrm{x}_{\mathrm{A}}+\mathrm{x}_{\mathrm{B}} \ln \mathrm{x}_{\mathrm{B}}+\mathrm{x}_{\mathrm{A}_{2} \mathrm{~B}} \ln \mathrm{x}_{\mathrm{A}_{2} \mathrm{~B}}\right)\right. \\
& \left.+\mathrm{RT}_{\mathrm{A}_{2} \mathrm{~B}} \ln \mathrm{k}\right]
\end{aligned}
$$

where $\omega_{12}, \omega_{13}$ and $\omega_{23}$ are pairwise interaction energies for the species $\mathrm{A}, \mathrm{B} ; \mathrm{A}, \mathrm{A}_{2} \mathrm{~B}$ and $\mathrm{B}$, $\mathrm{A}_{2} \mathrm{~B}$ respectively, $\mathrm{k}$ is equilibrium constant, $\mathrm{T}$ the temperature and $\mathrm{R}$ stands for the universal gas constant. The pairwise interaction energies and equilibrium constant are determined using the methods employed by Lele and Ramchandrarao [14].

Once the expressions for $\Delta \mathrm{G}$ is obtained, other thermodynamic and microscopic functions follow readily. Heat of mixing and entropy of mixing are related to $\Delta \mathrm{G}$ through standard thermodynamic relations

$$
\begin{aligned}
& \Delta \mathrm{H}=\Delta \mathrm{G}-\mathrm{T}\left(\frac{\partial \Delta \mathrm{G}}{\partial \mathrm{T}}\right)_{T, P} \\
& \Delta \mathrm{S}=\frac{\Delta \mathrm{H}-\Delta \mathrm{G}}{\mathrm{T}}
\end{aligned}
$$

Following Jordan [15] the activity coefficients $\gamma_{\mathrm{A}}, \gamma_{\mathrm{B}}$ and $\gamma_{\mathrm{A}_{2} \mathrm{~B}}$ of monomers and complex can be expressed in terms of pairwise interaction energies through

$$
\begin{aligned}
& R T \ln \gamma_{\mathrm{A}}=\mathrm{x}_{\mathrm{B}}^{2} \omega_{12}+\mathrm{x}_{\mathrm{A}_{2} \mathrm{~B}}^{2} \omega_{13}+\mathrm{x}_{\mathrm{B}} \mathrm{x}_{\mathrm{A}_{2} \mathrm{~B}}\left(\omega_{12}-\omega_{23}+\omega_{13}\right) \\
& \mathrm{RT} \ln \gamma_{\mathrm{B}}=\mathrm{x}_{\mathrm{A}_{2} \mathrm{~B}}^{2} \omega_{23}+\mathrm{x}_{\mathrm{A}}^{2} \omega_{12}+\mathrm{x}_{\mathrm{A}} \mathrm{x}_{\mathrm{A}_{2} \mathrm{~B}}\left(\omega_{23}-\omega_{13}+\omega_{12}\right) \\
& \mathrm{RT} \ln \gamma_{\mathrm{A}_{2} \mathrm{~B}}=\mathrm{x}_{\mathrm{A}}^{2} \omega_{13}+\mathrm{x}_{\mathrm{B}}^{2} \omega_{23}+\mathrm{x}_{\mathrm{B}} \mathrm{x}_{\mathrm{A}_{2} \mathrm{~B}}\left(\omega_{13}-\omega_{12}+\omega_{23}\right)
\end{aligned}
$$

And

$$
\ln \mathrm{k}=\ln \left(\frac{\mathrm{x}_{\mathrm{A}}^{2} \mathrm{x}_{\mathrm{B}}}{\mathrm{x}_{\mathrm{A}_{2} \mathrm{~B}}}\right)+\frac{\omega_{12}}{\mathrm{RT}}\left[2 \mathrm{x}_{\mathrm{B}}\left(1-\mathrm{x}_{\mathrm{B}}\right)+\mathrm{x}_{\mathrm{A}}\right]+\frac{\omega_{13}}{\mathrm{RT}}\left[2 \mathrm{x}_{\mathrm{A}_{2} \mathrm{~B}}\left(1-\mathrm{x}_{\mathrm{A}}\right)-\mathrm{x}_{\mathrm{A}}\right]+\frac{\omega_{23}}{\mathrm{RT}}\left[\mathrm{x}_{\mathrm{A}_{2} \mathrm{~B}}\left(1-2 \mathrm{x}_{\mathrm{B}}\right)-\mathrm{x}_{\mathrm{B}}\right]
$$

\section{Results and Discussion}

The compositional dependence of various species (figure 1) shows that the maximum association occurs at 60 at. pct. of $\mathrm{Pb}$. At this composition and $848 \mathrm{~K}$, about $52 \mathrm{~mol}$ pct. of the liquid alloy is associated. to be

The equilibrium constant and interaction energies for the alloy $\mathrm{PbK}$ in liquid state are found

$$
k=0.009, \quad \omega_{12}=-32523 \mathrm{~J} \mathrm{~mol}^{-1}, \omega_{13}=-14110 \mathrm{~J} \mathrm{~mol}^{-1} \text { and } \omega_{23}=-50596 \mathrm{~J} \mathrm{~mol}^{-1}
$$


All the interaction energies are found to be negative and show that left over $\mathrm{Pb}$ and $\mathrm{K}$ atoms are attracted to each other and to the complex.

Theoretical calculation of free energy of mixing for $\mathrm{PbK}$ liquid alloy shows that the minimum value of free energy of mixing for $\mathrm{PbK}$ is $-18.0 \mathrm{kJmol}^{-1}$ at $\mathrm{x}_{\mathrm{Ag}}=0.5$.

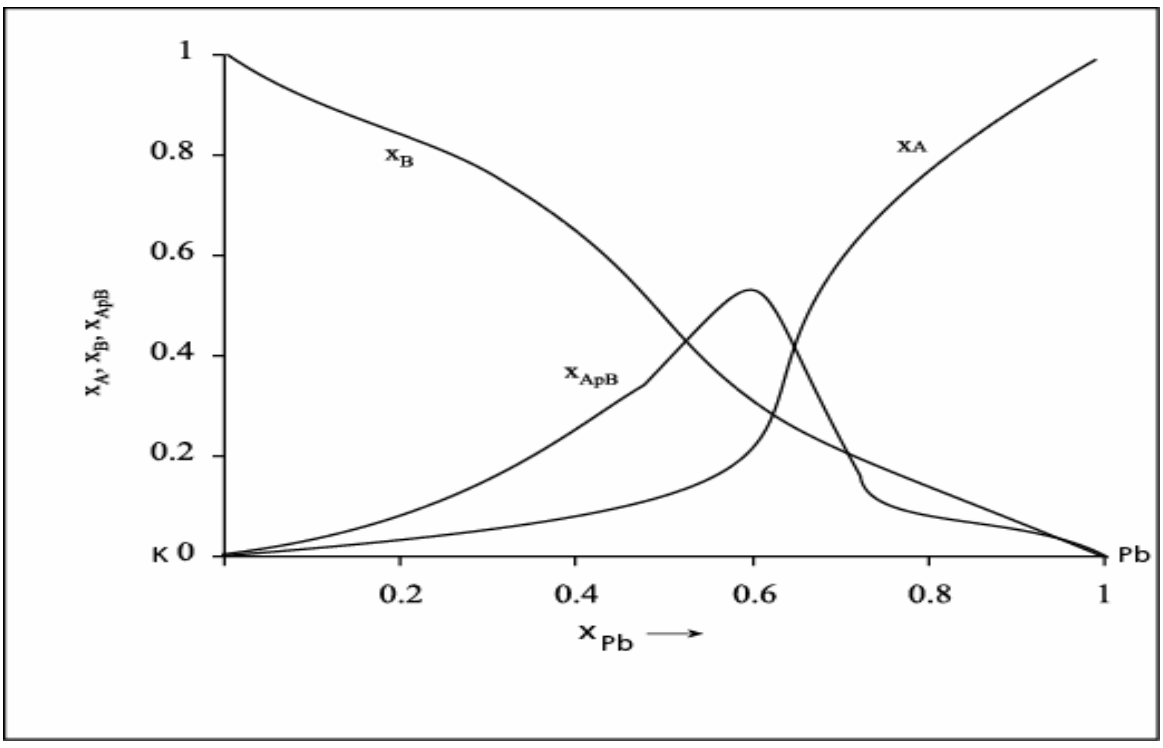

Figure 1 : Compositional dependence of mole fractions $x_{A}(A=P b)$,

$\mathrm{x}_{\mathrm{B}}(\mathrm{B}=\mathrm{K})$ and $\mathrm{x}_{\mathrm{ApB}}\left(\mathrm{AB}=\mathrm{Pb}_{2} \mathrm{~K}\right)$ versus $\mathrm{x}_{\mathrm{Pb}}$ (concentration of $\mathrm{Pb}$ in the liquid $\mathrm{PbK}$ solution $(848 \mathrm{~K})$

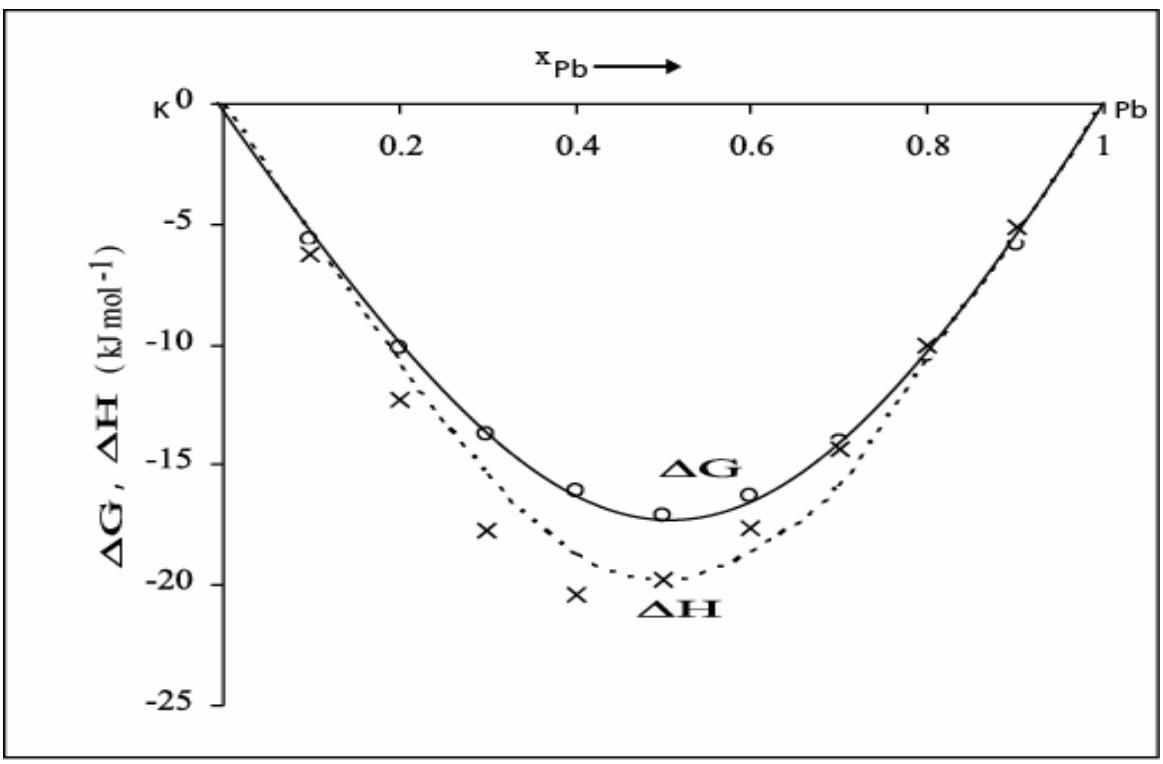

Figure 2 : Free energy of mixing $(\Delta \mathrm{G})$ versus $\mathrm{x}_{\mathrm{Pb}}$ (concentration of $\mathrm{Pb}$ ) in the liquid $\mathrm{PbK}$ solution $(848 \mathrm{~K}) ;(-)$ theory, (000) experiment [2] and Heat of mixing $(\Delta \mathrm{H})$ versus $\mathrm{x}_{\mathrm{Pb}}$ (concentration of $\left.\mathrm{Pb}\right)$ in the liquid $\mathrm{PbK}$ solution $(848 \mathrm{~K})$ $(\ldots \ldots \ldots)$ theory, $(X \times \times)$ experiment $[2]$. 
This minimum value of free energy of mixing of this alloy shows that $\mathrm{PbK}$ alloy in molten state is strongly interacting system. The agreement between calculated and observed value of free energy of mixing is good.

It is found from the analysis that the interaction energy parameters are temperature dependent. The best fit values of temperature dependent interaction energy parameters and heat of dissociation are found to be

$\frac{\partial \omega_{12}}{\partial \mathrm{T}}=+20 \mathrm{Jmol}^{-1} \mathrm{~K}^{-1}, \frac{\partial \omega_{13}}{\partial \mathrm{T}}=+40 \mathrm{Jmol}^{-1} \mathrm{~K}^{-1}, \quad \frac{\partial \omega_{23}}{\partial \mathrm{T}}=+45 \mathrm{Jmol}^{-1} \mathrm{~K}^{-1}$ and $\quad \mathrm{R} \mathrm{T}^{2} \frac{\partial \ln \mathrm{k}}{\partial \mathrm{T}}=$
$35500 \pm 1500 \mathrm{~J} \mathrm{~mol}^{-1}$
It is found from the analysis that the heat of mixing is negative at all concentration which is in agreement with experimental result. There is reasonable agreement between calculated and observed value of heat of mixing of $\mathrm{PbK}$ alloy in molten state. Figure 2 shows the comparison between the experimental and calculated values of free energy of mixing and heat of mixing. The calculated value and observed value of entropy of mixing are furnished in figure 3 . The calculated values of entropy of mixing do not always match in sign with experimental values. The deviation of calculated value of entropy of mixing is more below the concentration $\mathrm{x}_{\mathrm{Pb}}=0.6$. The discrepancy could be due to errors in enthalpy data or neglect of vibrational and electronic contributions on entropy. The deviations in entropy are, however, not significant enough to influence the agreement between other calculated and observed thermodynamic functions as shown in figure 2 .

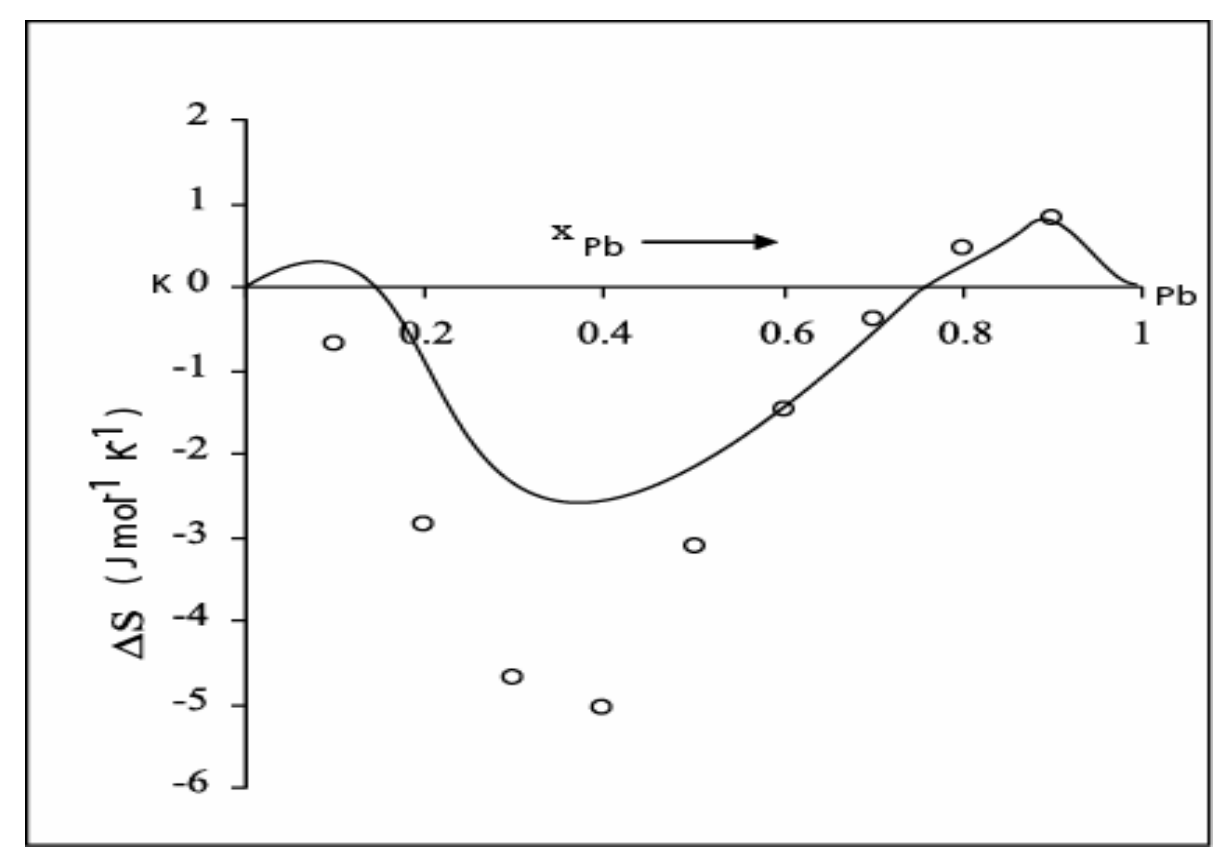

Figure 3 : Entropy of mixing $\left(\mathrm{S}_{\mathrm{M}}\right)$ versus $\mathrm{x}_{\mathrm{Pb}}($ concentration of $\mathrm{Pb})$ in the liquid $\mathrm{PbK}$ solution $(848 \mathrm{~K}) ;(-)$ theory, (000) experiment [2].

The deviations from ideal behaviour of the alloy can be incorporated into activities. The calculated and experimental activities are compared in figure 4. There is a good agreement between the calculated and experimental values. 


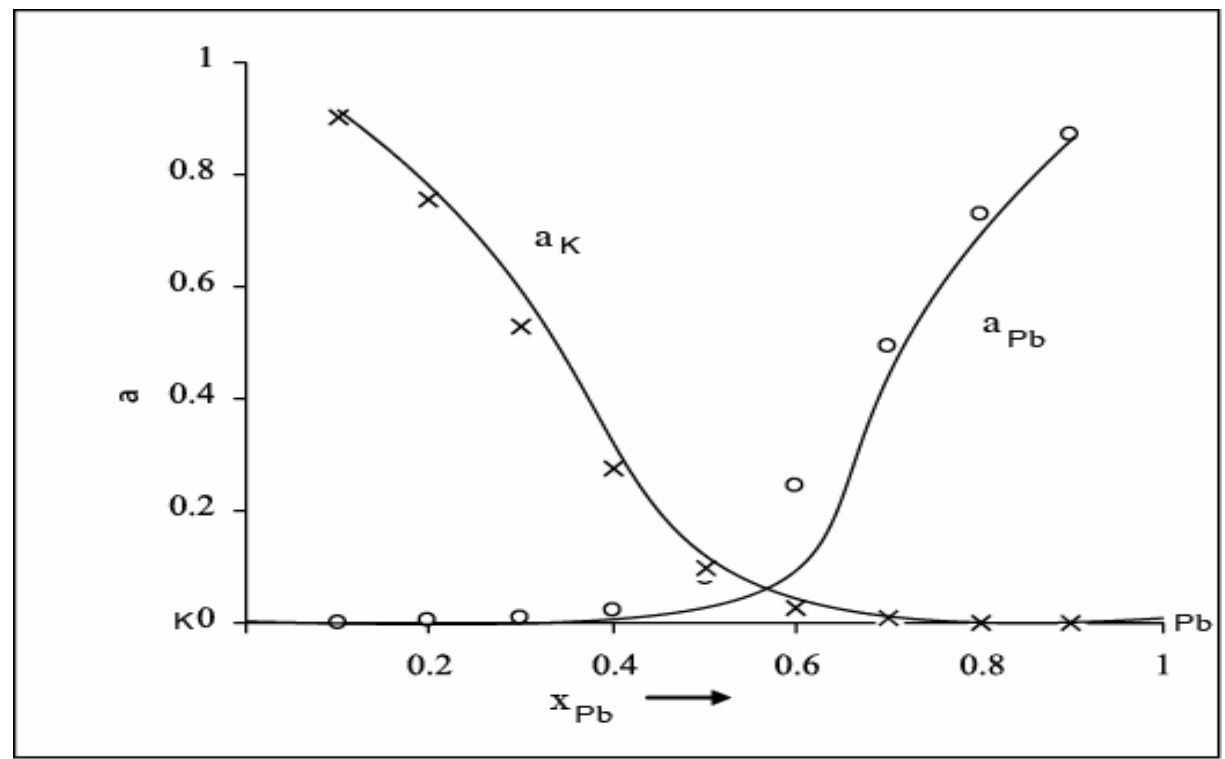

Figure 4: Activity (a) of $\mathrm{Pb}$ and $\mathrm{K}$ in liquid $\mathrm{KPb}$ solution $(848 \mathrm{~K}$ ) versus $\mathrm{x}_{\mathrm{Mg}} ;(-)$ theory, (०००) and (xxxx) experiment [2].

\section{Conclusion}

The analysis based on regular associated solution model shows that the $\mathrm{KPb}$ system is strongly interacting heterocoordination system and the pairwise interaction energies of this system depend strongly on temperature. Our theoretical analysis also shows that there exist complexes $\mathrm{Pb}_{2} \mathrm{~K}$ in $\mathrm{PbK}$ alloy in molten state.

\section{Acknowledgement}

D. Adhikari gratefully acknowledges UGC, Nepal for the financial support to conduct the research.

\section{References}

[1] P. P. Nath and R. N. Joarder, Indian J. Phys. ,84 (2010) 125.

[2] R. Hultgren, P. D Desai, D.T Hawkins, M. Gleser and K.K. Kelley, Selected values of the Thermodynamic Properties of Binary Alloys (Metals Park, Ohio: American Society for Metals (1973).

[3] D. Adhikari, B.P. Singh, I.S. Jha and B.K. Singh, J. Mol. Liqs., 156 (2010) 155.

[4] D. Adhikari, I.S. Jha and B.P. Singh, Phil. Mag. 90 (2010) 2687.

[5] A.B. Bhatia and D.E. Thornton, Phys. Rev., B 2 (1970) 3004.

[6] R.N. Singh, Can. J. Phys., 65(1987)309.

[7] K. Hoshino and W.H. Young, J. Phys. F. 10(1980) 1365.

[8] S.P. McAlister and E.D. Crozier, J. of Phys., C7 (1974) 3509.

[9] M. B. Yang, Y. L. Ma and F. S. Pan, Trans. Nonferrous Met. Soc. China, 19 (2009)1087.

[10] A.R Miedema, P.F de Chatel and F.R. Boer, Physica B, 100 (1980) 1.

[11] P. Chieux and H. Rupperesberg, J. Phys. Coll., 41(C8)(1980).

[12] D. Adhikari , I.S. Jha and B.P. Singh, Physica B, 405(2010) 1861.

[13] B.P. Singh, D. Adhikari and I.S. Jha, J. Non-Crystalline Solids, 356(2010) 1730.

[14] S. Lele and P. Ramchandrarao, Metall. Trans. B, 12 (1981) 659.

[15] A.S. Jordan, Metall. Trans., 1 (1970) 239. 